\title{
VALIDITY OF CERTAIN BEDSIDE TESTS IN PREDICTING DIFFICULT ENDOTRACHEAL INTUBATION
}

\author{
Jasim M Salman ${ }^{@}$, Sadad A Salman* \& Salam N Asfar ${ }^{*}$ \\ ${ }^{@}$ MB,ChB, DA, FICMS Anesth. \& I.C., Assistant Prof. of Anesthesiology, College of Medicine, \\ University of Basrah. " MB,ChB, Candidate of FICMS, Basrah Teaching Hospital. * MB,ChB, MSc \\ Anesth. Professor of Anesthesiology, College of Medicine, University of Basrah, Basrah, IRAQ.
}

\begin{abstract}
Unexpected difficult endotracheal intubation remains the main concern of anesthesiologists. This study aimed to compare validity and role of 7 bedside techniques of assessment used in predicting difficult intubation.

This prospective study included 80 patients scheduled for surgery. Before induction of anesthesia, bedside tests for predicting difficult intubation were done, these tests are: Prayer sign, Thyromental distance, Mallampati test, The inter incisor distance, Palm print test, Upper lip bite test, and Wilson scoring system. During induction of anesthesia, laryngoscopic view was evaluated. Values for each test were calculated and compared.

The results showed that, the highest sensitivity $(62.5 \%)$ was for Mallampati and thyromental distance but despite that, they differed in their specificity and predictive values. Upper lip bite was $12.5 \%$ sensitive but had one of the highest specificity alongside with Mallampati test. Thyromental distance was $34.7 \%$ specific. Mallampati classes of more than class I was strongly associated with difficult intubation. The mouth gap of more than $4 \mathrm{~cm}$ was marginally associated with difficult intubation. The predictor Wilson showed a significant association with difficult intubation if the score exceeded 3.5. The upper lip bite of more than class I was slightly associated with difficult intubation.

In conclusion, Mallampati classification and thyromental distance are superior to other available tests to predict difficult intubation, performing these two tests alone is relatively adequate to predict intubation difficulty.

Keywords: Difficult endotracheal intubation, The inter incisor distance, Wilson scoring system, Mallampati test, Palm print test, Prayer sign, Upper lip bite test, and Thyromental distance.
\end{abstract}

\section{Introduction}

The trip to get into the trachea 1 successfully is accompanied by a lot of events that one may expect anything; therefore any prior anticipation is wise. Such expectancy can be achieved by taking a thorough history and performing specific bedside examinations to act against the worry of unexpected intubation difficulty.

Assessment of anatomical and pathological difficulties can be done by a variety of tests:

The prayer sign: patients who are unable to completely oppose their hands (with no space between) or approximate the palmar surfaces of the interphalangeal joints due to stiff joint syndrome should be suspected to have changes in other joints and will potentially have difficult laryngoscopy and endotracheal intubation $^{1.2}$.

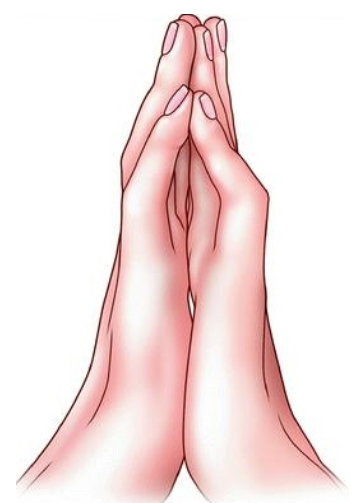

Cited from link.springer.com 
The thyromental distance: The distance between the mentum (chin) and the superior thyroid notch. A distance greater than 3 fingerbreadths is desirable for easy intubation ${ }^{3}$.

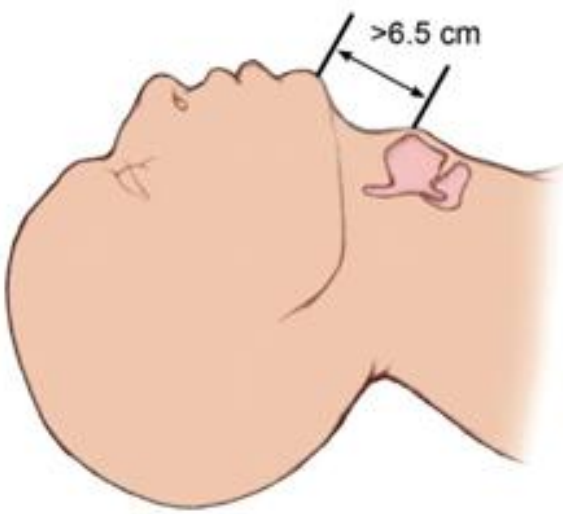

Cited from Anaesth.Intensive Care1988;16:329

The Mallampati test: Is a test that examines the size of the tongue in relation to the oral cavity. The more the tongue obstructs the view of the pharyngeal structures, the more difficult intubation may be. Mallampati Class I: The entire palatal arch, including the bilateral faucial pillars are visible down to the bases of the pillars, Class II: The upper part of the faucial pillars and most of the uvula are visible, Class III: Only the soft and hard palates are visible, and Class IV: Only the hard palate is visible. Easy intubation is expected in classes I \& $\mathrm{II}^{4}$.

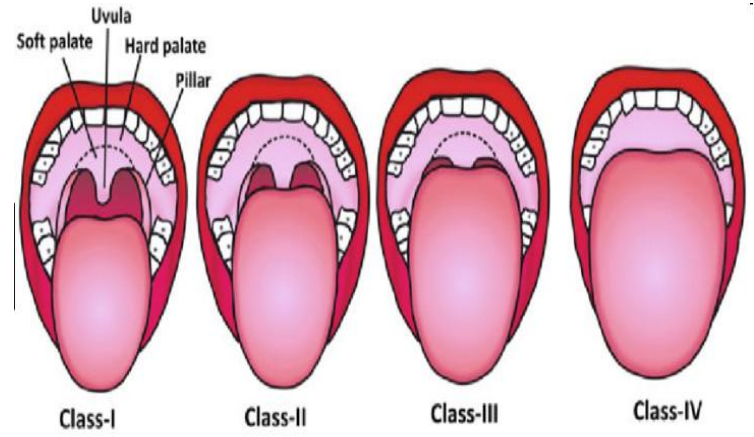

Cited from www.picsbud.com

The inter-incisor distance (Mouth opening): Between upper and lower incisors maximum distance of $3 \mathrm{~cm}$ or greater is desirable for intubation in an adult $^{5}$.

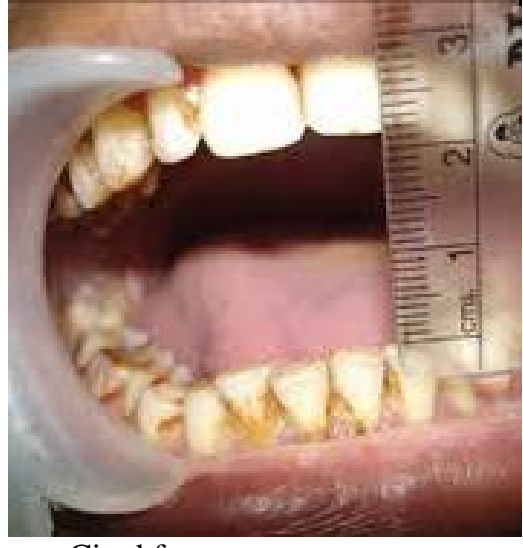

Cited from gas.carereamapp

Palm print test: The palm and fingers of the dominant hand of the patient is painted with black writing ink using a brush. The patient then presses the hand firmly against a white sheet of paper on a hard surface. Scoring is done as; Grade 0: All phalangeal areas are visible. Grade 1: Deficiency in inter phalangeal areas of 4th and/or 5th digit. Grade 2: Deficiency in inter phalangeal areas of 2nd to 5th digit. Grade 3: Only the tips of digits are seen. Grades $1 \& 2$ are good for easy Intubation ${ }^{6}$.

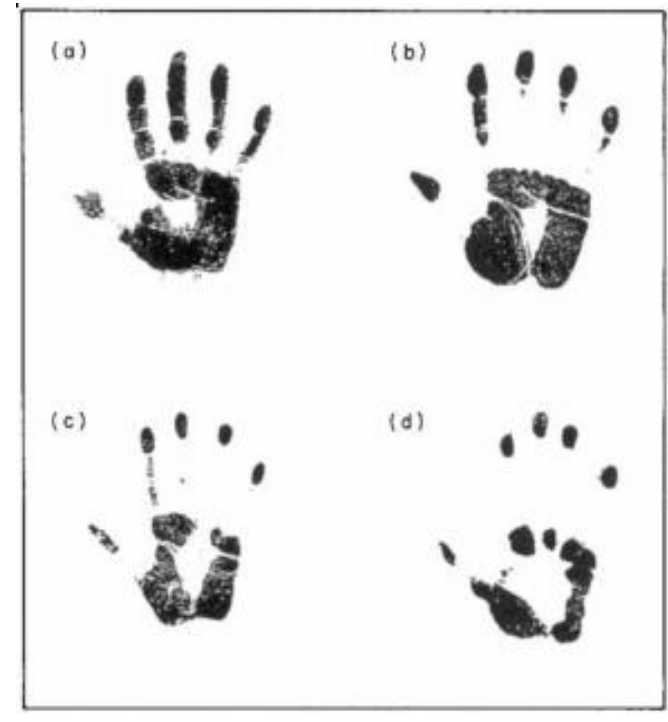

Cited from Anaesthesia,1990;45;1024

Upper lip bite test: A simple beside test asking the patient to bite his upper lip with his lower incisors. Class I: Lower incisors can bite the upper lip above the vermilion line (making the mucosa of the upper lip totally invisible). Class II: Lower incisors can bite the upper lip below the vermilion line (revealing a 
partially visible mucosa). Class III: Lower incisors cannot bite the upper lip. Classes I \& II are best for endotracheal intubation ${ }^{7,8}$.
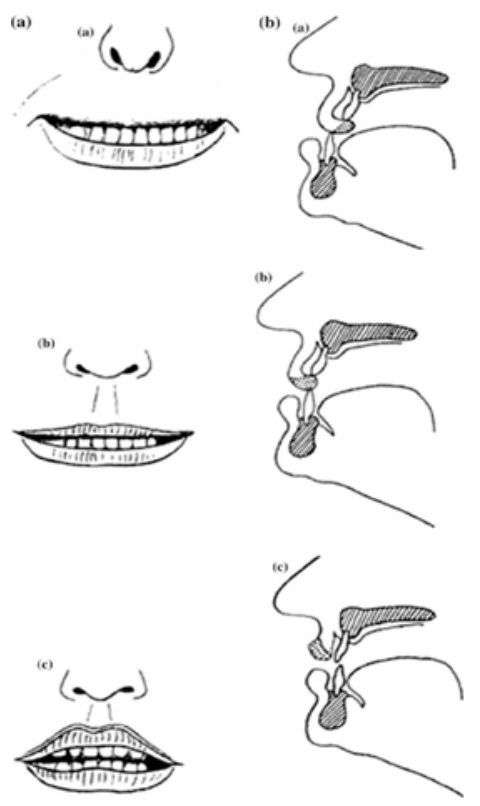

Cited from Anesthesia Analgesia, 2003;96:595

Wilson scoring system ${ }^{9}$ : includes 5 factors; weight, upper cervical spine mobility, jaw movement, receding mandible and buck teeth. Each factor scores $0-2$. Total score: $<5$ : Easy laryngoscopy and intubation. 6-7: Moderate difficulty. >8: Severe difficulty.

WILSON SCORE
\begin{tabular}{|l|l|l|l|}
\hline Parameter & 0 & 1 & 2 \\
\hline Weight $(\mathrm{kg})$ & $<90$ & $90-110$ & $>110$ \\
\hline $\begin{array}{l}\text { Head \& } \text { neck } \\
\text { movement }\end{array}$ & $>90$ & $=90$ & $<90$ \\
\hline IID & $>5$ & $=5$ & $<5$ \\
\hline $\begin{array}{l}\text { Receding mandible } \\
\text { Buck teeth }\end{array}$ & None & Moderate & severe \\
\hline
\end{tabular}
$\begin{aligned} & \leq 5 \text { Easy intubation; 8-10 very difficult } \\
& \text { intubation }\end{aligned}$

Cited from slideplayer.com

In this study, a qualitative comparison between those tests is done despite any limitation of each one or even any combination of them. The aim is to find out the best test for anticipating difficult endotracheal intubation that is highly sensitive and requires less patient cooperation.

\section{Patients \& Methods}

This prospective study was conducted on 80 adult patients American Society of Anesthesiologists (ASA) physical status classes I and II who were presented for elective surgery under general anesthesia with endotracheal intubation in Basrah Teaching Hospital in the period of January to December 2018.

Following institutional ethics and research committee's approval with obtaining an informed consent, their personal criteria and relevant history were recorded.

Examination to evaluate the intubation condition was performed using; Mallampati in conventional way at the level of the mouth, thyromental and interincisor distances were measured by a rigid ruler, the latter was when the patient fully opened his mouth, Wilson score was calculated, upper lip bite was estimated and both prayer and palm print signs were performed, the latter was by using talc powder against a black background.

Induction of anesthesia was carried out with propofol $2 \mathrm{mg} / \mathrm{kg}$ followed by a muscle relaxant, suxamethonium 1.5 $\mathrm{mg} / \mathrm{kg}$. The laryngoscopic outcome was evaluated and recorded. Data were analyzed by IBM SPSS statistics 23 (SPSS Inc., Chicago, IL, USA) software. Values for each test were calculated and compared.

The age and body mass index of the patients are demonstrated in table I. Other characteristics of the patients involved in this study are shown in table II.

The average age distribution was 44.2 year ranging between 15-85 years. The mean body mass index was $34.4 \mathrm{~kg} / \mathrm{m} 2$. The majority of the patients were females, accounting for $55 \%$. Most of the patients were white skin colored (95\%) and only $5 \%$ were black colored skin. Other features of the patients; were $10 \%$ diabetics, 30\% with obvious neck mass; mostly goiter. Negative history and examination was recorded in $38.75 \%$ and $63.75 \%$. 
Table I: Age and BMI distribution.

\begin{tabular}{|l|l|l|}
\hline Variable & range & average \\
\hline Age (years) & $15-85$ & 44.2 \\
\hline Body mass index (kg/m2) & 19.5 - 66.5 & 34.4 \\
\hline
\end{tabular}

Table II: Other characteristics of patients included in this study.

\section{Results}

\begin{tabular}{|l|l|l|}
\hline Variable & Frequency & Percentage \\
\hline Male gender & 36 & $45 \%$ \\
\hline Female gender & 44 & $55 \%$ \\
\hline White skin & 76 & $95 \%$ \\
\hline Black skin & 4 & $5 \%$ \\
\hline Diabetes mellitus & 8 & $10 \%$ \\
\hline Snoring & 7 & $8.75 \%$ \\
\hline Obstructive sleep apnea & 14 & $17.5 \%$ \\
\hline Neck mass & 24 & $30 \%$ \\
\hline Poor dentition & 4 & $5 \%$ \\
\hline Neck surgery & 1 & $1.25 \%$ \\
\hline Goiter & 24 & $30 \%$ \\
\hline Limited neck mobility & 5 & $6.25 \%$ \\
\hline Neck instability & 1 & $1.25 \%$ \\
\hline Negative history & 31 & $38.75 \%$ \\
\hline Negative examination & 51 & $63.75 \%$ \\
\hline
\end{tabular}

Ninety percent of the patients have easy endotracheal intubation and only $10 \%$ were intubated with difficulty as shown in table III.

Table III: The outcome of endotracheal intubation.

\begin{tabular}{|l|l|l|}
\hline Intubation & Number & Percentage \\
\hline Easy & 72 & $90 \%$ \\
\hline Difficult & 8 & $10 \%$ \\
\hline
\end{tabular}

The validity of different predictors is presented in table IV showing the highest sensitivity $(62.5 \%)$ was for Mallampati and thyromental distance with variable specificity $91.6 \%$ and $34.7 \%$ respectively.

Table IV: Validity of the tests.

\begin{tabular}{|l|l|l|l|l|}
\hline Test & Sensitivity & Specificity & $\begin{array}{l}\text { +ve predictive } \\
\text { value }\end{array}$ & $\begin{array}{l}\text {-ve predictive } \\
\text { value }\end{array}$ \\
\hline Mallampati test & $62.5 \%$ & $91.6 \%$ & $45.45 \%$ & $95.65 \%$ \\
\hline Thyromental distance & $62.5 \%$ & $34.7 \%$ & $9.61 \%$ & $89.28 \%$ \\
\hline Upper lip bite test & $12.5 \%$ & $90.2 \%$ & $12.5 \%$ & $90.27 \%$ \\
\hline Inter incisor test & $0 \%$ & $1 \%$ & $0 \%$ & $90 \%$ \\
\hline Palm print test & $0 \%$ & $1 \%$ & $0 \%$ & $90 \%$ \\
\hline Prayer's sign & $0 \%$ & $1 \%$ & $0 \%$ & $90 \%$ \\
\hline
\end{tabular}

Results of chi square test of significance of predictors in difficult intubation showed that Mallampati test has the best p-value of 0.037 followed by Thyromental distance test with $\mathrm{p}$ value of 0.064 as shown in table $\mathrm{V}$.

Table V: The best significant results of all tests

\begin{tabular}{|l|l|l|l|l|l|l|}
\hline Test & Outcome & Number & Mean & $\begin{array}{l}\text { Standard } \\
\text { deviation }\end{array}$ & $\begin{array}{l}\text { Standard } \\
\text { error mean }\end{array}$ & P-value \\
\hline \multirow{2}{*}{ Mallampati } & Easy & 72 & 1.9861 & 0.42767 & 0.05040 & 0.037 \\
\cline { 2 - 6 } & Difficult & 8 & 2.3750 & 0.91613 & 0.32390 & \\
\hline \multirow{2}{*}{$\begin{array}{l}\text { Thyromental } \\
\text { distance test }\end{array}$} & Easy & 72 & 5.9236 & 0.80342 & 0.09468 & 0.064 \\
\cline { 2 - 6 } & Difficult & 8 & 5.9375 & 0.94255 & 0.33324 & \\
\hline
\end{tabular}




\section{Discussion}

About one third of this study sample had no any predictor for difficult intubation. The results showed that there is $10 \%$ of the patients with difficult intubation. The highest sensitivity (62.5\%) was for Mallampati and thyromental distance but despite that they differed in their specificity and predictive values. Upper lip bite was $12.5 \%$ sensitive but had one of the highest specificity alongside with Mallampati. Thyromental distance was $34.7 \%$ specific. Nearly all the tests could highly negatively predict the difficult intubation.

According to this study, Mallampati classes of more than I was strongly associated with difficult intubation. On the other hand, the mouth gap of more than $4 \mathrm{~cm}$ was marginally associated with difficult intubation. The thyromental distance of more than $5 \mathrm{~cm}$ was insignificantly associated with difficult intubation. The predictor Wilson showed a significant association with difficult intubation if the score exceeded 3.5. The class of upper lip bite of more than 1 was marginally associated with difficult intubation.

Eighty patients were included in this study constituting a relatively small sample size and this due to the fact that many procedures were done under regional or spinal anesthesia. Most of the patients (95\%) were white skinned and only $5 \%$ were colored and this is consistent with the population structure in Basrah city were the majority are white race.

In this study, the incidence of difficult intubation was $10 \%$ with no recorded failure while other studies showed a wide range of difficulty and failure from $1 \%$ to $18 \%$ which might be attributed to population difference as well as sample size and types of patients. This high figure of easy intubation may be related to challenges in anesthesia practice over the years, good patient preparation with adequate muscle relaxation ${ }^{9-11}$.

In conclusion; Conventional Mallampati classification and thyromental distance remained superior to other available tests to predict difficult intubation, performing the above tests alone is relatively adequate to safeguard the process of airway control during anesthesia. So we recommend performing these simple two bedside tests in every patient prepared for surgery under general anesthesia as a part of preoperative assessment.

\section{References}

1. Rashid M Khan, Pradeep K Sharma, Naresh Kaul. Airway management in trauma. Indian J Anaesth. 2011 Sep-Oct; 55(5): 463-469.

2. Magboul M. Ali; The Dilemma of Airway Assessment and Evaluation. The Internet Journal of Anesthesiology. 2004 Volume 10 Number 1.

3. Practice guidelines for management of the difficult airway: an updated report by the American Society of Anesthesiologists Task Force on Management of the Difficult Airway. Anesthesiology 2003; 98 (5):1269-77

4. Frerk CM. Predicting difficult intubation. Anaesthesia 1991; 46 (12):1005-1008

5. Verghese C, Brimacombe JR. Survey of laryngeal mask airway usage in 11,910 patients: safety and efficacy for conventional and nonconventional usage. Anesth Analg 1996; 82: 129-133.

6. Gupta S, Sharma R, Jain D. Airway assessment - Predictors of a Difficult Airway. Indian Journal Of Anaesthetics 2005; 49(4) : $257-262$.

7. Khan ZH, Kashfi A, Ebrachimkhani EA: Comparison of the upper lip bite test (a simple new technique) with modified Mallampati classification in predicting difficulty in endotracheal intubation: a prospective blinded study. Anesth Analg, 2003; 96:595-599.

8. Zahid Hussain Khan and Shahriar Arbabi : Diagnostic value of the upper lip bite test in predicting difficulty in intubation with head and neck landmarks obtained from lateral neck X-ray, Indian J Anaesth. 2013; 57(4): 381-386.

9. Wilson ME, Spiegelhalter D, Robertson JA, Lesser P; Predicting difficult intubation. British Journal of Anaesthesia 1988, 61:211-216.

10. Tse JC, Rimm EB, Hussain A. Predicting difficult endotracheal intubation in surgical patients scheduled for general anesthesia: A prospective blind study. Anesth Analg. 1995; 81:254-258.

11. Naguib M, Scamman FL, O’Sullivan C, Aker J, Ross AF, Kosmach S, et al. Predictive performance of three multivariate difficult tracheal intubation models: A double-blind, case-controlled study. Anesth Analg. 2006; 102:818-824. 